\title{
Comparison of post-surgery follow-up methods in patients aged 80 years or older with non-metastatic colorectal cancer
}

\author{
Dong Min Seo ${ }^{1}$, Ji Won Park ${ }^{1,2,3}$, Dong Woon Lee', Yoon-Hye Kwon'1 ${ }^{1}$ In Ho Song' ${ }^{1}$, Seung-Bum Ryoo' ${ }^{1}$ Seung-Yong Jeong ${ }^{1,2,3}$, \\ Kyu Joo Park ${ }^{1,3}$ \\ ${ }^{1}$ Department of Surgery, Seoul National University College of Medicine, Seoul; \\ ${ }^{2}$ Colorectal Cancer Center, Seoul National University Cancer Hospital, Seoul; \\ ${ }^{3}$ Cancer Research Institute, Seoul National University College of Medicine, Seoul, Korea
}

Purpose: Studies investigating the appropriate post-surgery follow-up method for elderly patients with colorectal cancer are limited. Thus, the purpose of this study was to compare survival rates between two follow-up methods in patients aged 80 years or older who underwent surgery for colorectal cancer.

Methods: Between January 1, 2002 and December 31, 2010, 165 patients aged 80 years or older underwent curative resection for non-metastatic colorectal cancer at the Department of Surgery, Seoul National University Hospital. Sixty-six of these patients were excluded due to the lack of follow-up, while the remaining 99 were included in our study. These 99 patients were divided into the following two groups depending on their post-surgery follow-up method. Patients who underwent follow-up on a regular basis, which was defined as once every six months to one year, with carcinoembryonic antigen (CEA) and computed tomography (CT) comprised the Regular group, and those who received follow-up with CEA alone or underwent CT procedures once every two years or more comprised the Minimal group. Overall survival was analyzed with the log-rank test and Cox regression analysis.

Results: Of the 99 patients, 62 were in Regular group and 37 were in Minimal group. There was no difference in overall survival rate between the two post-surgery follow-up methods (regular group vs. minimal group: $51.6 \%$ vs. 50.9\% [5-year overall survival rate], $P=0.819$ ). Additionally, no significant differences was detected between the groups following multivariate analysis (harzard ratio $=0.907 ; 95 \%$ confidence interval $=0.460-1.788, P=0.777)$.

Conclusion: A significant survival gain was not observed between Regular and Minimal group. To draw a more definite conclusion, a multi-center randomized research study should be conducted.

Keywords: Surveillance, Carcinoembryonic antigen, Computed tomography, Overall survival, Colorectal cancer

\section{INTRODUCTION}

Colorectal cancer is the third most common cancer, following thyroid and stomach cancer, in Korea and ranks fourth in cancer mortality, as of 2014 [1]. Of carcinomas occurring in patients over age 65 , colorectal cancer ranks third among men and first among wom-

Received: Sep 30, 2017 Accepted: Dec 04, 2017

Correspondence to: Ji Won Park

Department of Surgery, Seoul National University College of Medicine,

101 Daehak-ro, Jongno-gu, Seoul 03080, Korea

Tel: +82-2-2072-2325, Fax: +82-2-766-3975

E-mail: sowisdom@gmail.com

Copyright (C) Korean Society of Surgical Oncology

This is an Open Access article distributed under the terms of the Creative Commons Attribution Non-Commercial License (http://creativecommons.org/licenses/by-nc/4.0) which permits unrestricted non-commercial use, distribution, and reproduction in any medium, provided the original work is properly cited. en, and the incidence rate increases with age. Considering that both global and Korean populations are aging [2], the treatment and management of colorectal cancer in patients of old age is an important issue.

Regarding the management of colorectal cancer, effective postoperative follow-up approaches have been investigated in a few studies, although a clear conclusion has not been provided [3-5]. Physical examination, carcinoembryonic antigen (CEA), computed tomography (CT), colonoscopy, and other procedures are used to follow-up patients with colorectal cancer after surgery. Recently, a study compared the net survival benefits between aggressive follow-ups using CT and minimal follow-ups based on CEA $[3,6]$ and found that survival rate did not differ between the two follow-up methods.

However, little research has been conducted on postoperative 
follow-up methods that are appropriate for patients with colorectal cancer who are of old age. The goal of this study was to compare the survival rates for different follow-up methods used in patients of 80 years of age or older who underwent surgery for colorectal cancer.

\section{METHODS}

Between January 1, 2002 and December 31, 2010, 165 patients aged 80 years or older underwent curative resection to treat primary colorectal cancer without metastasis at the Department of Surgery of Seoul National University Hospital. Of those patients, 99 were included in our study, after excluding 66 who did not visit the outpatient clinic following surgery.

Using hospital electronic medical records, the following data were retrospectively collected: body mass index at the time of diagnosis, sex, histories of diabetes and hypertension, American Society of Anesthesiologists (ASA) class, the site of primary cancer, preoperative CEA level, tumor size and grade, the presence of venous, lymphatic, and perineural invasions, cancer stage, postoperative follow-up method, history of pre- and postoperative adjuvant treatment, and survival length.

Postoperative follow-up methods were classified according to the physician's preference. Thus, patients were categorized into two groups, those for whom CEA and CT were performed on a regular basis, every 6 months to one year (regular group), and those who only received CEA testing or CT once every two years or more (minimal group).

Survival length was calculated from the date of surgery either to the date of death or to the date of the last follow-up. Overall survival rate was computed using the Kaplan-Meier method, and risk factors affecting overall survival rate were examined using the univariate log-rank test. Those variables found to be statistically significant in the univariate analysis were included in the multivariate Cox regression analysis, and additionally, the variables speculated to have an effect on survival rate (e.g., postoperative adjuvant therapy) were also included in the Cox model. Statistical analysis was performed using IBM SPSS statics ver. 22 (SPSS Inc., Chicago, IL, USA), and statistical significance was determined if a P-value was less than 0.05 .

\section{RESULTS}

Patient clinicopathological characteristics according to follow-up method are shown in Table 1 . There was a significant difference in stage between regular and minimal groups. Regarding pre- and postoperative adjuvant therapies, $38.7 \%$ of the Regular group and $2.7 \%$ of the Minimal group were treated with adjuvant therapy, and this difference was statistically significant. Aside from the two characteristics, between-group differences were not statistically significant for any of the following variables: age, sex, histories of diabetes and hypertension, ASA class, site of primary cancer, preoperative

Table 1. Baseline characteristics of study patients according to surveillance method

\begin{tabular}{|c|c|c|c|}
\hline Characteristic & $\begin{array}{l}\text { Regular } \\
(n=62)\end{array}$ & $\begin{array}{l}\text { Minimal } \\
(n=37)\end{array}$ & P-value \\
\hline Age (yr) & $82.8 \pm 3.0$ & $84.0 \pm 3.2$ & 0.069 \\
\hline Body mass index $\left(\mathrm{kg} / \mathrm{m}^{2}\right)$ & $22.0 \pm 2.7$ & $21.1 \pm 3.0$ & 0.167 \\
\hline Sex & & & $>0.999$ \\
\hline Male & $38(61.3)$ & $23(62.2)$ & \\
\hline Female & $24(38.7)$ & 14 (37.8) & \\
\hline Diabetes mellitus & & & $>0.999$ \\
\hline$(-)$ & $51(82.3)$ & 30 (83.3) & \\
\hline$(+)$ & $11(17.7)$ & $6(16.7)$ & \\
\hline Hypertension & & & 0.295 \\
\hline$(-)$ & $34(54.8)$ & $15(41.7)$ & \\
\hline$(+)$ & $28(45.2)$ & $21(58.3)$ & \\
\hline American Society of Anesthesiologists score & & & 0.111 \\
\hline Score 1,2 & $52(86.7)$ & $27(73.0)$ & \\
\hline Score $\geq 3$ & 18 (13.3) & $10(27.0)$ & \\
\hline Location & & & 0.609 \\
\hline Colon & $49(79.0)$ & 31 (83.8) & \\
\hline Rectum & $13(21.0)$ & $6(16.2)$ & \\
\hline Carcinoembryonic antigen $(\mathrm{ng} / \mathrm{mL})$ & & & 0.621 \\
\hline$<5$ & $45(77.6)$ & $25(71.4)$ & \\
\hline$\geq 5$ & $13(22.4)$ & $10(28.6)$ & \\
\hline Tumor grade & & & $>0.999$ \\
\hline Low & 53 (93.0) & $34(94.4)$ & \\
\hline High & $4(7.0)$ & $2(5.6)$ & \\
\hline Tumor size (cm) & $5.22 \pm 2.41$ & $4.97 \pm 2.1$ & 0.600 \\
\hline Venous invasion & & & 0.154 \\
\hline$(-)$ & 51 (91.1) & $32(100)$ & \\
\hline$(+)$ & $5(8.9)$ & $0(0.0)$ & \\
\hline Perineural invasion & & & $>0.999$ \\
\hline$(-)$ & 46 (85.2) & $27(87.1)$ & \\
\hline$(+)$ & $8(14.8)$ & $4(12.9)$ & \\
\hline Lymphatic invasion & & & 0.491 \\
\hline$(-)$ & $39(66.1)$ & $27(75.0)$ & \\
\hline$(+)$ & $20(33.9)$ & $9(25.0)$ & \\
\hline Stage & & & 0.007 \\
\hline 0,1 & $9(14.5)$ & $11(29.7)$ & \\
\hline 2 & $22(35.5)$ & $19(51.4)$ & \\
\hline 3 & $31(50.0)$ & $7(18.9)$ & \\
\hline Adjuvant therapy & & & $<0.001$ \\
\hline$(-)$ & 38 (61.3) & 36 (97.3) & \\
\hline$(+)$ & 24 (38.7) & $1(2.7)$ & \\
\hline
\end{tabular}

Values are presented as mean \pm standard deviation or number (\%). 
Table 2. Univariate analysis of prognostic factors for overall survival

\begin{tabular}{|c|c|c|c|}
\hline \multirow[b]{2}{*}{ Variables } & \multicolumn{3}{|c|}{$5-y r$} \\
\hline & No. & $\begin{array}{l}\text { Survival } \\
\text { rate }(\%)\end{array}$ & P-value \\
\hline Age & & & 0.041 \\
\hline$<83$ & 48 & 60.3 & \\
\hline$\geq 83$ & 51 & 42.8 & \\
\hline Body mass index $\left(\mathrm{kg} / \mathrm{m}^{2}\right)$ & & & 0.496 \\
\hline$<21.9$ & 52 & 45.7 & \\
\hline$\geq 21.9$ & 47 & 57.4 & \\
\hline Sex & & & 0.799 \\
\hline Male & 61 & 55.7 & \\
\hline Female & 38 & 43.8 & \\
\hline Diabetes mellitus & & & 0.796 \\
\hline$(-)$ & 81 & 50.4 & \\
\hline$(+)$ & 17 & 58.8 & \\
\hline Hypertension & & & 0.765 \\
\hline$(-)$ & 49 & 53.1 & \\
\hline$(+)$ & 49 & 50.5 & \\
\hline American Society of Anesthesiologists score & & & 0.006 \\
\hline 1,2 & 79 & 58.0 & \\
\hline$\geq 3$ & 18 & 27.8 & \\
\hline Location & & & 0.110 \\
\hline Colon & 80 & 53.6 & \\
\hline Rectum & 19 & 42.1 & \\
\hline Carcinoembryonic antigen (ng/mL) & & & 0.145 \\
\hline$<5$ & 70 & 55.6 & \\
\hline$\geq 5$ & 23 & 43.5 & \\
\hline Tumor grade & & & $<0.001$ \\
\hline Low & 87 & 51.5 & \\
\hline High & 6 & 16.7 & \\
\hline Tumor size (cm) & & & 0.102 \\
\hline$<5$ & 46 & 56.1 & \\
\hline$\geq 5$ & 51 & 47.1 & \\
\hline Venous invasion & & & $<0.001$ \\
\hline$(-)$ & 83 & 55.2 & \\
\hline$(+)$ & 5 & 0 & \\
\hline Perineural invasion & & & 0.071 \\
\hline$(-)$ & 73 & 53.2 & \\
\hline$(+)$ & 12 & 33.3 & \\
\hline Lymphatic invasion & & & 0.121 \\
\hline$(-)$ & 66 & 56.1 & \\
\hline$(+)$ & 29 & 37.4 & \\
\hline Stage & & & 0.109 \\
\hline 0,1 & 20 & 70.0 & \\
\hline 2 & 41 & 41.5 & \\
\hline 3 & 38 & 52.6 & \\
\hline Adjuvant therapy & & & 0.427 \\
\hline$(-)$ & 74 & 48.5 & \\
\hline$(+)$ & 25 & 60.0 & \\
\hline Follow-up & & & 0.819 \\
\hline Regular & 62 & 51.6 & \\
\hline Minimal & 37 & 50.9 & \\
\hline
\end{tabular}

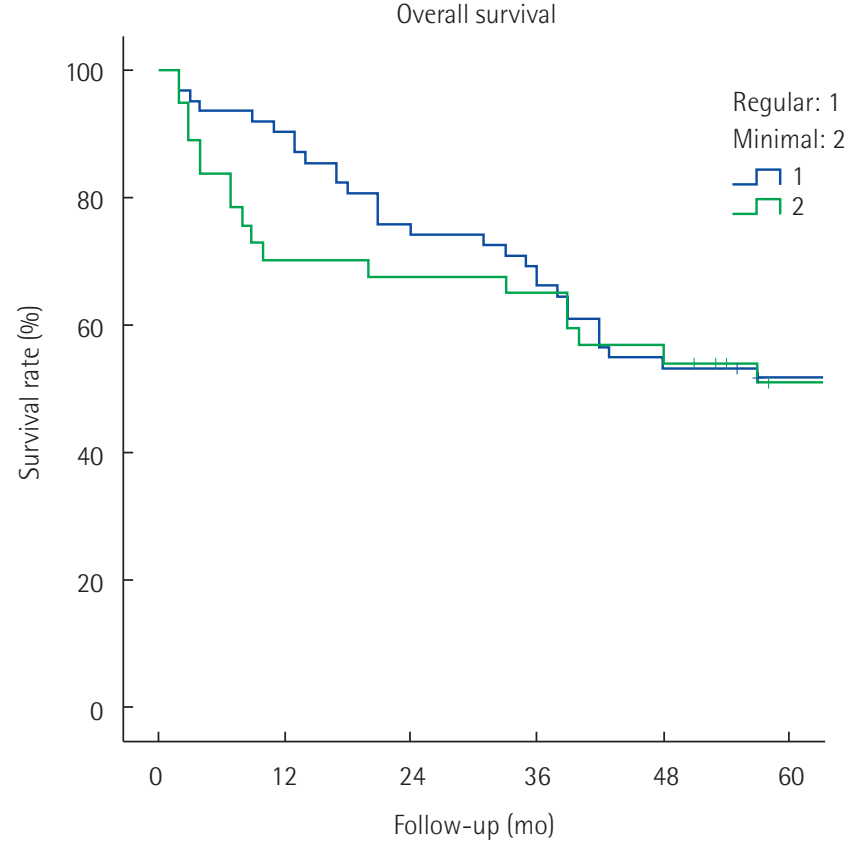

Fig. 1. Overall survival graph according to follow-up method.

Table 3. Multivariate analysis of prognostic factors for overall sur vival

\begin{tabular}{|c|c|c|c|}
\hline Variables & $\begin{array}{l}\text { Hazard } \\
\text { ratio }\end{array}$ & $\begin{array}{l}\text { 95\% Confi- } \\
\text { dence interval }\end{array}$ & P-value \\
\hline \multicolumn{4}{|l|}{ Age (yr) } \\
\hline$<83$ vs. $\geq 83$ & 1.414 & $0.756-2.643$ & 0.278 \\
\hline \multicolumn{4}{|c|}{ American Society of Anesthesiologists score } \\
\hline 1,2 vs. $\geq 3$ & 2.632 & $1.238-5.596$ & 0.012 \\
\hline \multicolumn{4}{|l|}{ Tumor grade } \\
\hline Low vs. high & 5.965 & $1.731-20.551$ & 0.005 \\
\hline \multicolumn{4}{|l|}{ Venous invasion } \\
\hline (+) vs. (-) & 6.205 & $1.854-20.764$ & 0.003 \\
\hline Stage & & & 0.334 \\
\hline 2 vs. 0,1 & 2.117 & $0.781-5.742$ & 0.141 \\
\hline 3 vs. 0,1 & 1.782 & $0.606-5.236$ & 0.294 \\
\hline \multicolumn{4}{|l|}{ Adjuvant therapy } \\
\hline (+) vs. (-) & 1.730 & $0.719-4.160$ & 0.221 \\
\hline \multicolumn{4}{|l|}{ Follow-up } \\
\hline Regular vs. minimal & 0.907 & $0.406-1.788$ & 0.777 \\
\hline
\end{tabular}

CEA, tumor size and grade, and presence of lymphatic, venous, or perineural invasions.

The 5-year overall survival rate during the follow-up period was $51.4 \%$, in all patients. In the univariate analysis of overall survival, age, ASA class, tumor grade, and venous invasion showed statistically significant differences between the two groups (Table 2). The overall survival rate did not differ according to post-surgery follow-up methods (regular group vs. minimal group: 51.6\% vs. 

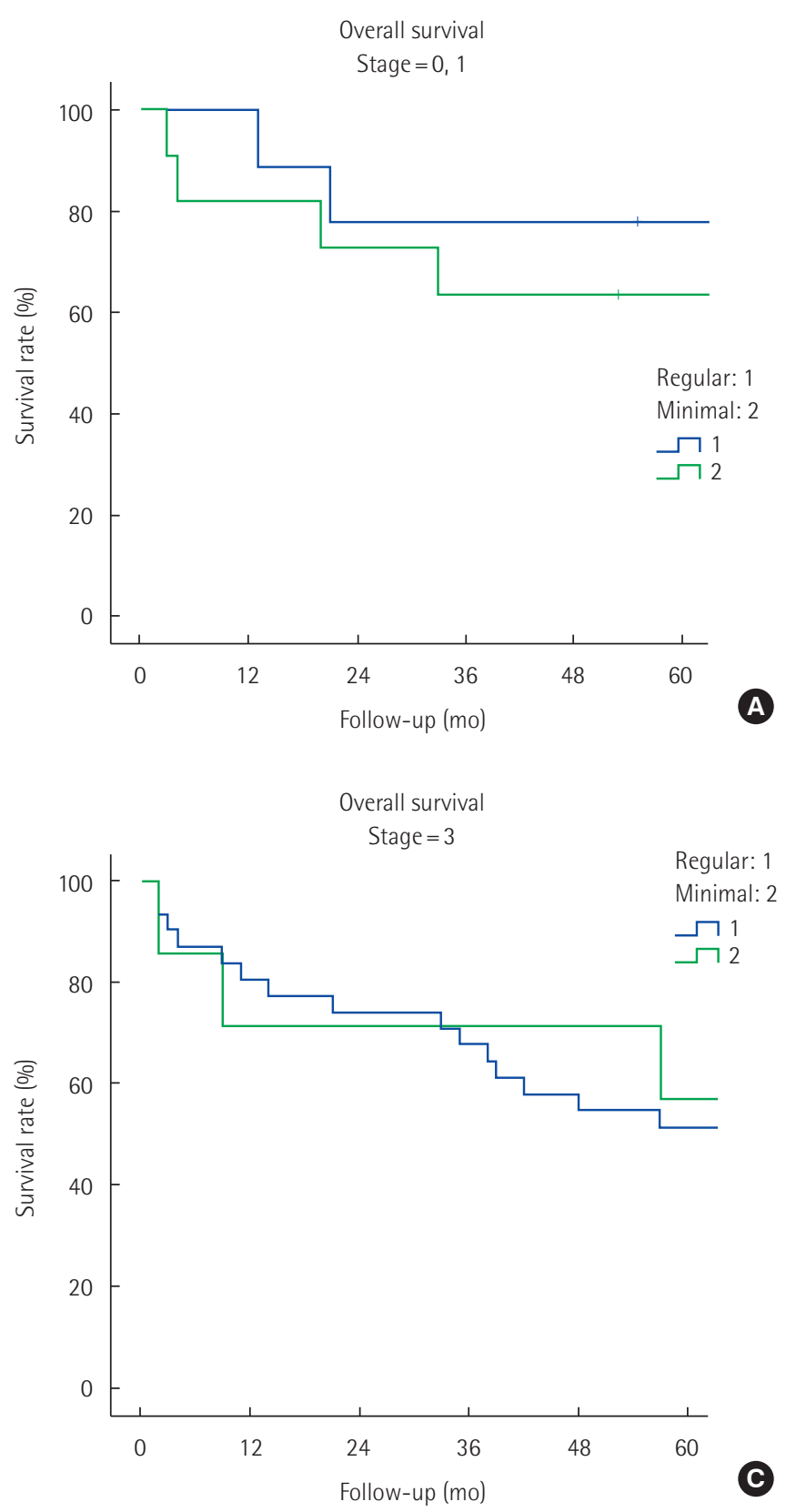

50.9\% [5-year overall survival rate], $\mathrm{P}=0.819$ ) (Fig. 1).

In the multivariate analysis of overall survival, ASA class, tumor grade, and venous invasion were statistically significant. Again, Regular and Minimal groups did not show significant between-group differences (harzard ratio $=0.907 ; 95 \%$ confidence interval $=0.406$ $-1.788, \mathrm{P}=0.777)$ (Table 3).

Because a between-group difference was found for cancer stage, differences in survival rates were examined for each stage. The result showed that overall survival rates did not differ between Regular and Minimal groups in any of the cancer stages (stages 0 and 1 : $77.8 \%$ vs. $63.6 \%$, [5-year overall survival rate], $\mathrm{P}=0.536$, stage 2 : $40.9 \%$ vs. $42.1 \%$, [5-year overall survival rate], $\mathrm{P}=0.525$, stage 3 :

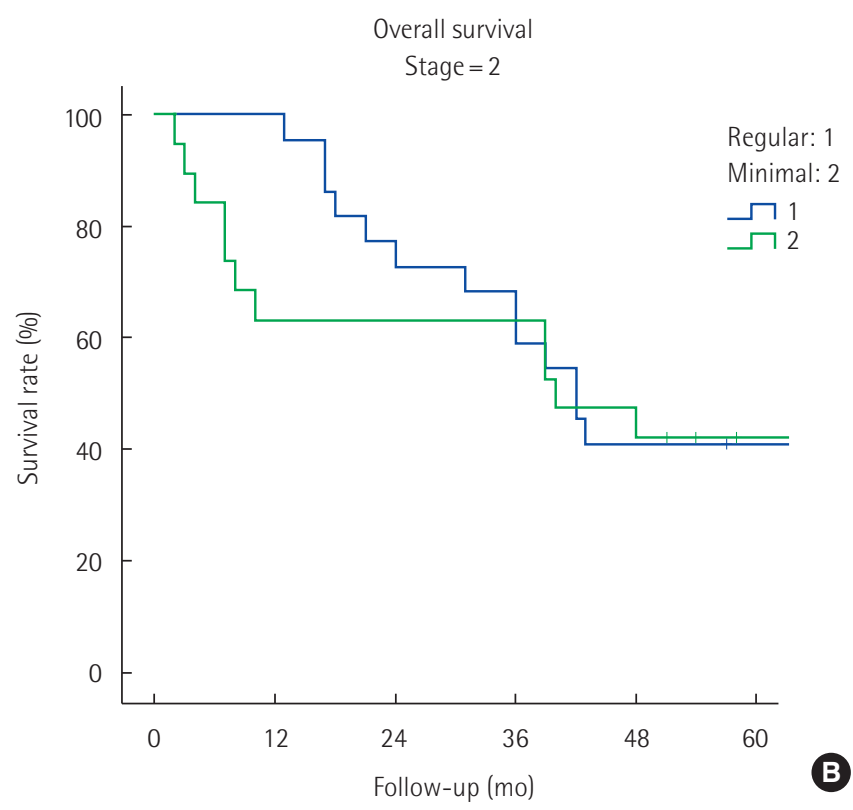

Fig. 2. Overall survival graph according to follow-up method in each stage. (A) Stage 0 and 1. (B) Stage 2. (C) Stage 3.

$51.6 \%$ vs. $57.1 \%$ [5-year overall survival rate], $\mathrm{P}=0.613$ ) (Fig. 2).

\section{DISCUSSION}

Follow-up methods for patients with colorectal cancer who underwent surgery have been investigated in a few studies. The primary tests used to follow-up patients with colorectal patients after surgery are CT, CEA, and colonoscopy, of which CEA and CT have proven useful in identifying metastases and recurrences [3-5]. The FACS clinical trial, which was conducted with patients who underwent surgery for colorectal cancer, compared treatable recurrences among patient groups that underwent follow-up with either CT, 
CEA, or a combination of CT and CEA, as well as a group of patients who underwent follow-up when symptoms were present. The findings showed that the rate of treatable recurrences was higher in the groups who underwent follow-up with CT alone, CEA alone, and the combination of CT and CEA, in comparison to the group of patients who underwent follow-up in the presence of symptoms. Interestingly, there was no great gain in the group of patients who underwent follow-up with both CT and CEA in comparison to groups that were followed-up with only one test [6]. Renehan et al. [7] performed a meta-analysis to examine survival and recurrence rates for each of the follow-up methods defined in the study and found that CEA and imaging tests, including CT, were performed in most cases of intense follow-up, in comparison to the control group. The authors reported that survival rate was higher and recurrence was found sooner in the intense follow-up group.

In the present study, a net survival gain was not observed between patients with non-metastatic colorectal cancer who were aged 80 years or older and underwent regular follow-ups, with CEA and CT every six months to one year and those who underwent follow-up with CEA alone or with CT once every two or more years. The goal of follow-up is to improve survival rates by finding and treating recurrences in proper time. However, the frequent follow-up of elderly patients, as outpatients, is not easy and the treatment of patients with a recurrent cancer is also difficult, even when the recurrence is found. For these reasons, the effectiveness of follow-up is speculated to be low. In this study, additional analysis conducted on recurrence showed that recurrence occurred in 23 patients, 21 of whom were from the regular group and two who were from the minimal group. Of the 21 patients in the Regular group, 12 (57.1\%) were not treated and only three (14.3\%) were expected to show a complete remission with additional surgery and adjuvant chemotherapy. Considering that the rates of patients not treated for recurrence and of those expected to show a complete remission are low, the gain in the Regular follow-up group does not seem great. However, it was not possible to compare this observation with the Minimal group because of the small number of cases that showed recurrence. Patients of old age may avoid follow-up with CT because two outpatient visits are required (i.e., one to take CT and a second to find out the results), since CT findings are not available on the day of testing. Based on the findings of the present study, we should consider following up patients of old age, after surgery only, with annual CEA examinations, rather than with the combination of CEA and CT or with CT at longer intervals.

Survival of patients with colorectal cancer who are of old age is influenced not only by cancer recurrence and progression but also other underlying diseases and old age itself [8-10]. In the present study, we focused on overall survival, considering that patients may die of another cause even without cancer progression. The overall survival rate by stage (stages 0 and 1,70.0\%; stage 2, 41.5\%; stage $3,52.6 \%$ ) was lower than previously reported, and the multivariate analysis showed that survival rate was influenced by ASA class. These findings suggest the importance of managing other diseases, as well as cancer, in patients of old age. In this study, we were not able to examine deaths by cancer and deaths by other diseases separately, due to lack of cause of death data.

This study is significant, as studies have rarely examined the prognoses of the follow-up methods in elderly patients with colorectal cancer, particularly in those aged 80 years or older. However, there were a few limitations in this study. First, many patients were not followed-up as outpatients $(66 / 165=40 \%)$. Nonetheless, there were no differences, with the exception of sex, between patients who were excluded due to lack of follow-up and those who were included in our study (Supplemental Table S1). Therefore, the study findings are not greatly influenced by the exclusion of these patients. Second, this study was a single-center retrospective investigation, and the number of patients per group was small. Hence, it was possible for Type 2 errors to occur, and although there were significant between-group differences, they could be insignificant due to small sample size. We found that tumor grade was a significant factor affecting survival rate, but the interpretation was limited due to the small number of patients. Third, selection bias exists, since the mean stage and rate of patients treated with adjuvant therapy were higher in the Regular group than in the Minimal group. To adjust for bias, multivariate and stage-specific analyses were performed, although a definite conclusion could not be drawn due to the small sample size. To obtain clearer evidence, a multi-center, randomized study with a large sample size is needed.

To summarize, the present study demonstrated that in patients who are aged 80 years or older and undergo surgery for non-metastatic colorectal cancer, regular follow-up with CEA and CT once every six months to one year does not provide a significant net survival benefit over follow-ups with CEA alone or with CT at longer intervals. However, this study was retrospective and based on a small number of patients, so there are limitations on drawing conclusions about the follow-up method most appropriate for this patient population. To draw a definite conclusion, a multi-center randomized study should be conducted.

\section{CONFLICT OF INTEREST}

No potential conflict of interest relevant to this article was reported. 


\section{ACKNOWLEDGMENTS}

This research was partly supported by the Basic Science Research Program through the National Research Foundation of Korea (NRF) funded by the Ministry of Education (No. NRF-2017R1D1A1B03036191) and partly supported by grant No. 0420170600 (2017-1249) from the SNUH Research Fund.

\section{SUPPLEMENTARY MATERIALS}

Supplemental Table S1. Baseline characteristics between included (follow-up) and excluded patients (follow-up loss).

Supplemental data can be found at: https://doi.org/10.14216/ kjco.1700139

\section{REFERENCES}

1. Jung KW, Won YJ, Oh CM, Kong HJ, Lee DH, Lee KH. Cancer statistics in Korea: incidence, mortality, survival, and prevalence in 2014. Cancer Res Treat 2017;49:292-305.

2. Kim IK. Population aging in Korea: social problems and solutions. J Sociol Soc Welf 1999;26:107-23.

3. Buie WD, Attard JA. Follow-up recommendations for colon cancer. Clin Colon Rectal Surg 2005;18:232-43.
4. Steele SR, Chang GJ, Hendren S, Weiser M, Irani J, Buie WD, et al. Practice guideline for the surveillance of patients after curative treatment of colon and rectal cancer. Dis Colon Rectum 2015;58:71325.

5. Peng Y, Zhai Z, Li Z, Wang L, Gu J. Role of blood tumor markers in predicting metastasis and local recurrence after curative resection of colon cancer. Int J Clin Exp Med 2015;8:982-90.

6. Primrose JN, Perera R, Gray A, Rose P, Fuller A, Corkhill A, et al. Effect of 3 to 5 years of scheduled CEA and CT follow-up to detect recurrence of colorectal cancer: the FACS randomized clinical trial. JAMA 2014;311:263-70.

7. Renehan AG, Egger M, Saunders MP, O’Dwyer ST. Impact on survival of intensive follow up after curative resection for colorectal cancer: systematic review and meta-analysis of randomised trials. BMJ 2002;324:813.

8. Turrentine FE, Wang H, Simpson VB, Jones RS. Surgical risk factors, morbidity, and mortality in elderly patients. J Am Coll Surg 2006;203:865-77.

9. Widdison AL, Barnett SW, Betambeau N. The impact of age on outcome after surgery for colorectal adenocarcinoma. Ann R Coll Surg Engl 2011;93:445-50.

10. Hamel MB, Henderson WG, Khuri SF, Daley J. Surgical outcomes for patients aged 80 and older: morbidity and mortality from major noncardiac surgery. J Am Geriatr Soc 2005;53:424-9. 
Supplement Table S1. Baseline characteristics between included (follow-up) and excluded patients (follow-up loss)

\begin{tabular}{|c|c|c|c|}
\hline Characteristic & Included patients $(n=99)$ & Excluded patients $(n=66)$ & P-value \\
\hline Age (yr) & $83.3 \pm 3.168$ & $84.0 \pm 3.2$ & 0.559 \\
\hline Body mass index $\left(\mathrm{kg} / \mathrm{m}^{2}\right)$ & $21.6 \pm 2.8$ & $22.2 \pm 3.6$ & 0.269 \\
\hline $\begin{array}{l}\text { Sex } \\
\text { Male } \\
\text { Female }\end{array}$ & $\begin{array}{l}61(61.6) \\
38(38.4)\end{array}$ & $\begin{array}{l}28(42.4) \\
38(57.6)\end{array}$ & 0.017 \\
\hline $\begin{array}{l}\text { Diabetes mellitus } \\
\qquad \begin{array}{l}(-) \\
(+)\end{array}\end{array}$ & $\begin{array}{l}81 \text { (82.7) } \\
17(17.3)\end{array}$ & $\begin{array}{l}54 \text { (81.8) } \\
12(18.2)\end{array}$ & 0.714 \\
\hline $\begin{array}{l}\text { Hypertension } \\
\qquad \begin{array}{l}(-) \\
(+)\end{array}\end{array}$ & $\begin{array}{l}49(50.0) \\
49(50.0)\end{array}$ & $\begin{array}{l}32(48.5) \\
34(51.5)\end{array}$ & 0.875 \\
\hline $\begin{array}{l}\text { ASA score } \\
\text { Score 1, } 2 \\
\text { Score } \geq 3\end{array}$ & $\begin{array}{l}79 \text { (81.4) } \\
18 \text { (18.6) }\end{array}$ & $\begin{array}{r}53 \text { (86.9) } \\
8 \text { (13.1) }\end{array}$ & 0.509 \\
\hline $\begin{array}{l}\text { Location } \\
\text { Colon } \\
\text { Rectum }\end{array}$ & $\begin{array}{l}80 \text { (80.8) } \\
19(19.2)\end{array}$ & $\begin{array}{l}50(75.8) \\
16(24.2)\end{array}$ & 0.444 \\
\hline $\begin{array}{l}\text { CEA (ng/mL) } \\
\quad<5 \\
\quad \geq 5\end{array}$ & $\begin{array}{l}70(75.3) \\
23(24.7)\end{array}$ & $\begin{array}{l}47(74.6) \\
16(25.4)\end{array}$ & 1.000 \\
\hline $\begin{array}{l}\text { Tumor grade } \\
\text { Low } \\
\text { High }\end{array}$ & $\begin{array}{l}87(87.9) \\
12(12.1)\end{array}$ & $\begin{array}{r}59(89.4) \\
7(10.6)\end{array}$ & $\begin{array}{l}0.809 \\
0.179\end{array}$ \\
\hline Tumor size $(\mathrm{cm})$ & $5.13 \pm 2.32$ & $5.67 \pm 2.58$ & \\
\hline 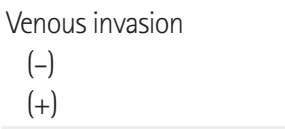 & $\begin{array}{c}83(94.3) \\
5(5.7)\end{array}$ & $\begin{array}{c}32 \text { (95.2) } \\
3(4.8)\end{array}$ & $>0.99$ \\
\hline $\begin{array}{l}\text { Perineural invasion } \\
(-) \\
(+)\end{array}$ & $\begin{array}{l}73(85.9) \\
12(14.1)\end{array}$ & $\begin{array}{r}50(89.3) \\
6(10.7)\end{array}$ & 0.615 \\
\hline $\begin{array}{l}\text { Lymphatic invasion } \\
\qquad \begin{array}{l}(-) \\
(+)\end{array}\end{array}$ & $\begin{array}{l}66(69.5) \\
29(30.5)\end{array}$ & $\begin{array}{l}52 \text { (78.8) } \\
14(21.2)\end{array}$ & 0.209 \\
\hline $\begin{array}{c}\text { Stage } \\
0,1 \\
2 \\
3\end{array}$ & $\begin{array}{l}20(20.2) \\
41(41.4) \\
38(38.4)\end{array}$ & $\begin{array}{l}13(19.7) \\
31(47.0) \\
22(33.3)\end{array}$ & 0.755 \\
\hline $\begin{array}{l}\text { Adjuvant therapy } \\
(-) \\
(+)\end{array}$ & $\begin{array}{l}74(74.7) \\
25(25.3)\end{array}$ & $\begin{array}{r}57(86.4) \\
9(13.6)\end{array}$ & 0.080 \\
\hline
\end{tabular}

Values are presented as mean \pm standard deviation or number $(\%)$. 